\title{
Phospholipid Biosynthesis in the Moderately Halophilic Bacterium Vibrio costicola During Adaptation to Changing Salt Concentrations
}

\author{
By N.J. RUSSELL, ${ }^{1 *}$ M. KOGUT ${ }^{1}$ AND M. KATES ${ }^{2}$ \\ ${ }^{1}$ Department of Biochemistry, University College, PO Box 78, Cardiff CFI IXL,UK \\ 2 Department of Biochemistry, University of Ottawa, Ottawa, Ontario K1N 9B4, Canada
}

(Received 4 October 1984 ; revised 12 November 1984)

\begin{abstract}
The metabolism of phospholipids in Vibrio costicola, a moderately halophilic bacterium, has been investigated in relation to sudden changes in salinity. Both the absolute and relative rates of biosynthesis of phosphatidylglycerol and phosphatidylethanolamine depend on the salt concentration of the medium; a sudden rise in salt concentration has an instantaneous inhibitory effect on phospholipid biosynthesis, but this inhibition lessens as the bacteria adapt to the higher salinity. There is no turnover of phospholipids during isotonic growth, nor when the salt concentration is suddenly altered. The alterations in biosynthetic rates of phosphatidylglycerol and phosphatidylethanolamine that occur after sudden changes in salt concentration are consistent with the known compositional changes. We conclude that the mechanisms of changes in phospholipid composition during adaptation to raised or lowered salt concentrations are not necessarily the same.
\end{abstract}

\section{INTRODUCTION}

Vibrio costicola can grow over a wide range of $\mathrm{NaCl}$ concentrations (Kushner, 1978) due to phenotypic adaptation rather than selection of variants (Forsyth \& Kushner, 1970). It has been shown that $V$. costicola and some other moderate halophiles contain greater proportions of negatively charged phospholipids in their membranes when growing at higher salt concentrations (Komaratat \& Kates, 1975; Ohno et al., 1979; Hanna et al., 1984). It has been suggested that this helps to counter the high $\mathrm{Na}^{+}$concentration at the membrane surface (Hiramatsu et al., 1980).

We have shown recently that the phospholipid composition of $V$. costicola altered during the period immediately following a change in external salinity (Kogut \& Russell, 1984), and that these changes appeared to be an integral part of the process of adaptation to growth at a new salt concentration. The major phospholipids of $V$. costicola are phosphatidylethanolamine (PE; neutral, zwitterionic) and phosphatidylglycerol (PG; negatively charged). The increase in the relative proportion of $P G$ seen after a sudden rise in external salinity occurred during the lag in growth following the salt shift before the culture had adopted the growth rate appropriate to the new salt concentration; the same was true of the relative decrease in PG content following a sudden fall in external salinity (Kogut \& Russell, 1984). These experiments, however, gave no indication as to whether the changes in the ratio of PE to PG were brought about by increased biosynthesis or degradation of the negatively charged or neutral phospholipids. Nor was there any indication whether the changes that occurred in response to an increase in external salinity (shift-up) were mediated by the same mechanism(s) as the reciprocal changes in phospholipid composition that occurred in response to a decrease in external salinity (shift-down).

In order to determine whether these changes in phospholipid composition involve biosynthesis or degradation of specific lipids we have used radioactive precursors of phospholipids to probe the biosynthetic capabilities of the bacteria at different stages during their phenotypic adaptation to growth in different salt concentrations. 


\section{METHODS}

Organism and cultural conditions. Vibrio costicola (NRCC 3700) was obtained from Dr D. J. Kushner, University of Ottawa, and was maintained on nutrient agar containing $1 \mathrm{M}-\mathrm{NaCl}$. Bacteria were grown in a liquid medium containing $0.5 \%(\mathrm{w} / \mathrm{v})$ tryptone (Difco), $0.5 \%(\mathrm{w} / \mathrm{v})$ proteose peptone (Difco) and $1 \mathrm{M}-$ or $3 \mathrm{M}-\mathrm{NaCl}$ at $30^{\circ} \mathrm{C}$ in an orbital shaker at 120 r.p.m.

To change the salt concentration of the culture medium during growth in the shift experiments, the cultures were grown to exponential phase $\left(\mathrm{OD}_{500}=0.2-0.8\right)$ and sedimented by centrifugation at $600 \mathrm{~g}$ for $5 \mathrm{~min}$ at room temperature followed by resuspension in pre-warmed medium with the indicated salt concentration. Growth was monitored by measurements of $\mathrm{OD}_{500}$ in a Cecil CE 373 spectrophotometer using cuvettes of $1 \mathrm{~cm}$ light path. Under these conditions $\mathrm{OD}_{500}=1.0$ is equivalent to a concentration of $0.3 \mathrm{mg} \mathrm{dry} \mathrm{wt} \mathrm{ml}^{-1}$ (Kogut, unpublished).

Radioisotopes. Sodium $\left[1^{-14} \mathrm{C}\right]$ acetate $\left(1.90 \mathrm{GBq} \mathrm{mmol}^{-1}\right)$ and $\left[{ }^{32} \mathrm{P}\right]$ orthophosphate (carrier-free, $\left.185 \mathrm{MBq}\right)$ were purchased from Amersham.

Lipid labelling and extraction. For pulse-labelling, $15 \mathrm{ml}$ portions of an exponentially growing culture were added to $1.5 \mathrm{ml}$ sodium $\left[1{ }^{-14} \mathrm{C}\right]$ acetate in $100 \mathrm{ml}$ Erlenmeyer flasks, at the times indicated in the legends to the figures, and incubated under the same conditions as the main culture. Rates of $\left[{ }^{14} \mathrm{C}\right]$ acetate incorporation into lipids were determined as follows: $3 \mathrm{ml}$ samples of the labelled cultures were withdrawn at 15, 30 and 45 min after the addition of $\left[{ }^{14} \mathrm{C}\right]$ acetate and the lipids extracted by the method of Bligh \& Dyer (1959) as detailed by Kates (1972), by rapidly mixing the culture sample with $11.25 \mathrm{ml}$ methanol/chloroform $(2: 1, \mathrm{v} / \mathrm{v})$ to give a ratio of $2: 1: 0.8$ for methanol, chloroform and water; after approximately $1 \mathrm{~h}$ a further $3.75 \mathrm{ml}$ of chloroform and $3.75 \mathrm{ml}$ of water were added to bring the solvent composition to $1: 1: 0.9$ (methanol/chloroform/water). The mixture was centrifuged briefly, the upper phase removed, and the chloroform layer washed twice with.$\llcorner-14 \mathrm{ml}$ methanol/water $(10: 9, \mathrm{v} / \mathrm{v})$. The final washed chloroform extracts of lipids from each sample were evaporated to dryness under $\mathrm{N}_{2}$, and the lipid residues redissolved in a known volume of chloroform (0.2-0.4 ml).

Measurement of $\left[{ }^{14} \mathrm{C}\right]$ acetate incorporation in phospholipids. A small volume of each of the total lipid extracts was pipetted into scintillation vials, the solvent evaporated, and $10 \mathrm{ml}$ of a scintillation cocktail $(0.3 \mathrm{~g}$ POPOP, 5.0 g PPO, $130 \mathrm{ml}$ methanol and $100 \mathrm{ml}$ Beckman Bio-Solv 3 made up to 1 litre with toluene) added and the ${ }^{14} \mathrm{C}$ radioactivity counted using a programmable LKB Rack-Beta liquid scintillation spectrometer. Counting efficiency was estimated by the external standards ratio method.

The remainder of each lipid extract was separated by TLC on commercial silica gel plates (Baker, Phillipsburg, NJ, USA) developed in chloroform/methanol/acetic acid/water (85:15:10:3.5, by vol.). The phospholipids were visualized with iodine vapour and the areas of individual spots scraped into scintillation vials for determination of the radioactivity as above.

PE and PG were identified by staining with ninhydrin and phosphate reagents, and by analysis of mild alkaline deacylation products (Kates, 1972), and co-chromatography with authentic standards (Sigma and Serdary Research Laboratories, London, Ontario, Canada). Cardiolipin, identified as above, and some unidentified minor spots, were also counted in the initial experiments, but the sum of their counts never reached $10 \%$ of the total counts in the lipid extracts, and were therefore not included in subsequent experiments.

Measurement of phospholipid turnover Phospholipid turnover was measured by a pulse-chase method using sodium $\left[1-{ }^{14} \mathrm{C}\right]$ acetate or $\left[{ }^{32} \mathrm{P}\right]$ orthosphosphate. Two exponentially growing cultures $(50 \mathrm{ml}$ in $250 \mathrm{ml}$ Erlenmeyer flasks) in medium containing $1 \mathrm{M}-\mathrm{NaCl}$ were pulse-labelled with $\left[1{ }^{14} \mathrm{C}\right]$ acetate $(185 \mathrm{kBq}$ per flask, final concentration $1.8 \mu \mathrm{M}$ ) for $60 \mathrm{~min}$. For the 'chase' the cultures were centrifuged separately at $600 \mathrm{~g}$ in a bench centrifuge for $5 \mathrm{~min}$ at room temperature, and washed with medium containing $1 \mathrm{M}-\mathrm{NaCl}$; the pellet from one culture was resuspended in $50 \mathrm{ml}$ of fresh, prewarmed medium containing $1.8 \mathrm{~mm}$-sodium acetate and $1 \mathrm{M}-\mathrm{NaCl}$ ( $1 \mathrm{M}$ control) and the other in $50 \mathrm{ml}$ of medium containing $1.8 \mathrm{~mm}$-sodium acetate and $3 \mathrm{M}-\mathrm{NaCl}$ (shift-up). A $3 \mathrm{ml}$ sample from each flask was removed immediately for lipid extraction and analysis, and determination of radioactivity in phospholipids (as described above). The remainder of each culture was incubated at $30^{\circ} \mathrm{C}$ in an orbital shaker, and $3 \mathrm{ml}$ samples extracted at intervals during a $6 \mathrm{~h}$ chase period.

The pulse-chase experiments were repeated as above, except that $3.7 \mathrm{MBq}$ [ ${ }^{32} \mathrm{P}$ ]orthophosphate per flask (final concentration $11 \mu \mathrm{M}$ ) was used for pulse-labelling, and $11 \mathrm{mM}-\mathrm{Na}_{2} \mathrm{HPO}_{4}$ was included in the $1 \mathrm{M}-$ or $3 \mathrm{M}-\mathrm{NaCl}$ resuspension media for the chase.

\section{RESULTS}

We first established conditions for pulse-labelling with sodium $\left[1-{ }^{14} \mathrm{C}\right]$ acetate which would give linear incorporation into the various phospholipids during growth of cultures at different salt concentrations. Under the conditions used (Fig. 1) incorporation of $\left[{ }^{14} \mathrm{C}\right]$-acetate into the major phospholipids, PE and PG, was linear for at least $60 \mathrm{~min}$ in $1 \mathrm{M}$ - and $3 \mathrm{M}-\mathrm{NaCl}$ medium. Control experiments (not shown) established that the manipulations involved in the shift 


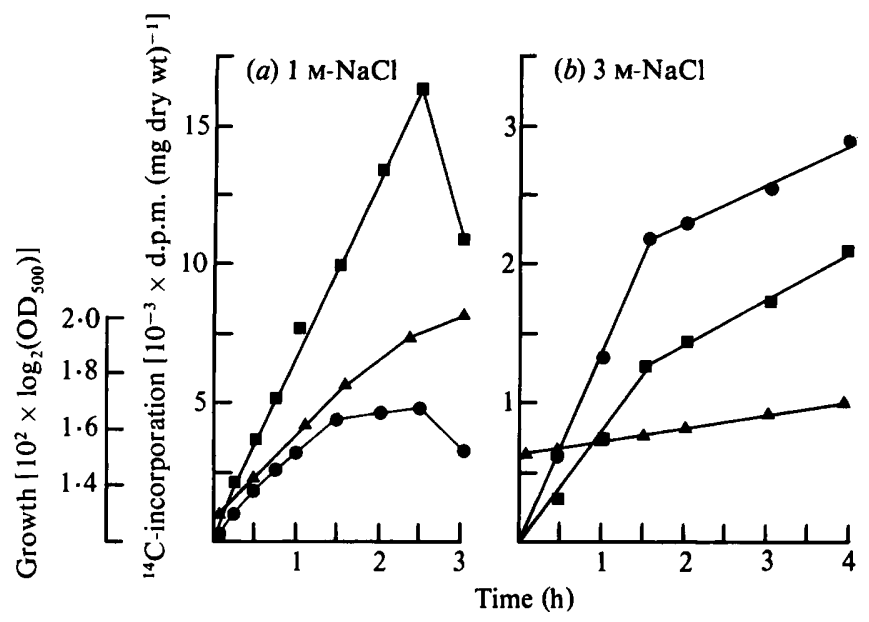

Fig. 1. Incorporation of $\left[{ }^{14} \mathrm{C}\right]$ acetate into phospholipids of $V$. costicola during growth. Cultures were grown in medium containing $1 \mathrm{M}-\mathrm{NaCl}(a)$ or $3 \mathrm{M}-\mathrm{NaCl}(b)$. Sodium $\left[1-{ }^{14} \mathrm{C}\right]$ acetate was added to give a final concentration of $3.7 \mathrm{kBq} \mathrm{ml}^{-1}$. Samples of $3 \mathrm{ml}$ were removed for lipid extraction and isolation and determination of radioactivity in PE $(\square)$ and PG (O). Growth was monitored as $\mathbf{O D}_{500}(\boldsymbol{A})$.

procedures, i.e. centrifugation and resuspension, did not affect the incorporation of $\left[{ }^{14} \mathrm{C}\right]$ acetate or the growth rate. The rates of incorporation depended on the salt concentration of the medium in two respects: first, the rates of incorporation into all major phospholipids in cultures growing in $1 \mathrm{M}-\mathrm{NaCl}$ medium were greater than those of cultures growing in $3 \mathrm{M}-\mathrm{NaCl}$ medium, which is in line with the faster growth rate in $1 \mathrm{M}-\mathrm{NaCl}$ (Hanna et al., 1984; Kogut \& Russell, 1984); second, at the lower $\mathrm{NaCl}$ concentration $\left[{ }^{14} \mathrm{C}\right]$ acetate incorporation into $\mathrm{PE}$ occurred at about twice the rate of that into $\mathrm{PG}$, whereas at the higher salt concentration the rate of incorporation into PG was almost double that for PE.

An exponentially growing culture was subjected to a sudden increase in salt concentration of the growth medium (shift-up) from $1 \mathrm{M}-$ to $3 \mathrm{M}-\mathrm{NaCl}$, and the rates of phospholipid synthesis measured by pulse-labelling samples of the cultures with $\left[{ }^{14} \mathrm{C}\right]$ acetate at intervals after the shiftup. Immediately after shift-up, culture growth almost stopped but after a lag period of $2-3 \mathrm{~h}$ the culture adapted to the new growth rate characteristic of the new salt concentration (Fig. $2 a$ ). A control culture (1 $\mathrm{M}$ control) was treated in the same manner, except that it was resuspended in medium containing $1 \mathrm{M}-\mathrm{NaCl}$. During the period immediately after the shift-up (S1, Fig. 2a) the rate of incorporation of $\left[{ }^{14} \mathrm{C}\right]$ acetate into $\mathrm{PG}$ rose to nearly twice that of incorporation into $\mathrm{PE}$ ( $\mathrm{S} 1$, Fig. $2 b$ ). Both rates, however, were considerably lower than those for the $1 \mathrm{M}$ control. Further samples of the shifted culture were removed at intervals during the subsequent $6-6.5 \mathrm{~h}$ (S2-S5) and similarly tested for their ability to incorporate $\left[{ }^{14} \mathrm{C}\right]$ acetate into phospholipids. When the ${ }^{14} \mathrm{C}$-incorporation rates into $\mathrm{PG}$ and $\mathrm{PE}$ are plotted as a function of time after shift-up (Fig. $2 c$ ), the rate of $\left[{ }^{14} \mathrm{C}\right]$ acetate incorporation into $P G$ is seen to rise sharply during the first $3.5 \mathrm{~h}$ after the shift (S1-S3, Fig. 2b,c) that is during that period when the major changes in growth rate occurred. At the same time the incorporation rate into $\mathrm{PE}$ slowly increased after the initial dramatic fall from that characteristic of growth in $1 \mathrm{M}-\mathrm{NaCl}(1 \mathrm{M}$ control, Fig. $2 b)$. During the later stages (S3-S5, Fig. 2b,c) of the adaptation to growth in $3 \mathrm{M}-\mathrm{NaCl}$, the incorporation rates into $P G$ and $P E$ approached steady levels, with that for PG remaining above that for PE when the final growth rate was reached (S5, Fig. $2 a, b$ ).

To measure phospholipid turnover, cultures growing in medium with $1 \mathrm{M}-\mathrm{NaCl}$ were prelabelled for $1 \mathrm{~h}$ with sodium $\left[1-{ }^{14} \mathrm{C}\right]$ acetate or $\left[{ }^{32} \mathrm{P}\right]$ orthophosphate (pulse), and each centrifuged and washed with $1 \mathrm{M}-\mathrm{NaCl}$ and divided into two parts; for each isotopic precursor one part was resuspended in $1 \mathrm{M}-\mathrm{NaCl}$ medium and the other 'shifted-up' in $3 \mathrm{M}-\mathrm{NaCl}$ medium, both lacking radioactive precursor but containing a 1000 -fold excess of $\left[{ }^{12} \mathrm{C}\right]$ acetate or $\left[{ }^{31} \mathrm{P}\right]$ phosphate over the original concentration of radioactive precursor (chase). Samples 

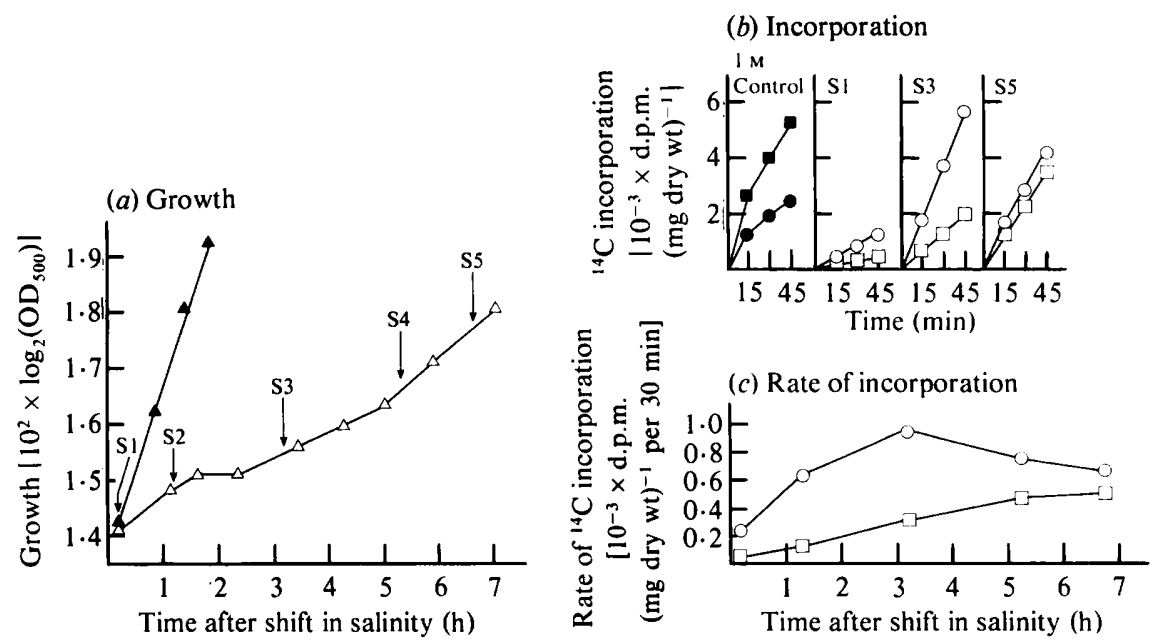

Fig. 2. Rates of incorporation of $\left[{ }^{1+} \mathrm{C}\right]$ acetate into phospholipids of $V$. costicola following an increase in medium salinity. A culture growing in medium containing $1 \mathrm{M}-\mathrm{NaCl}$ was shifted-up to $3 \mathrm{M}-\mathrm{NaCl}$, as detailed in Methods, and its growth monitored as $\operatorname{OD}_{500}(\mathrm{a} ; \Delta) ;$ a control culture was centrifuged and resuspended in medium with $1 \mathrm{~m}-\mathrm{NaCl}(\mathrm{a} ; \mathbf{\Delta})$. At $10 \mathrm{~min}(\mathrm{~S} 1), 1.25 \mathrm{~h}(\mathrm{~S} 2), 3.25 \mathrm{~h}(\mathrm{~S} 3), 5.25 \mathrm{~h}$ (S4) and $6.75 \mathrm{~h}(\mathrm{~S} 5)$, as indicated in (a), after the shift-up $15 \mathrm{ml}$ portions of the shifted culture were added to $55.5 \mathrm{kBq}$ sodium $\left[1-{ }^{1+} \mathrm{C}\right]$ acetate in separate $100 \mathrm{ml}$ Erlenmeyer flasks, and the incorporation of ${ }^{1+} \mathrm{C}$ radioactivity into PE $(\square)$ and $\mathrm{PG}(\mathrm{O})$ determined; time-courses of incorporation for S1, S3 and S5 are shown also in $(b)$. The $1 \mathrm{M}$-control culture was tested similarly at the same time as $\mathrm{S} 1$, and the timecourses of incorporation of ${ }^{14} \mathrm{C}$ radioactivity in PE $(\square)$ and PG $(O)$ are shown in $(b)$. From such curves the rate of ${ }^{1+} \mathrm{C}$ incorporation was calculated, and the data for all shift-up time-points is summarized in (c). Note that in this figure (and in Figs 3 and 4) control samples are represented by closed symbols, and shifted samples by open symbols.

were removed over the same time-course as used in the experiments described above (Fig. $2 a-c$ ) and the radioactivity in PE and PG determined. There was no loss of radioactivity from the phospholipids derived from $\left[{ }^{14} \mathrm{C}\right]$ acetate when bacteria were resuspended in medium containing $1 \mathrm{M}-\mathrm{NaCl}$ (Fig. 3a). Immediately following a shift-up to $3 \mathrm{M}-\mathrm{NaCl}$ there was a sudden loss of ${ }^{14} \mathrm{C}$ radioactivity, more so from $\mathrm{PE}$ than from $\mathrm{PG}$, but there was no further loss during the subsequent adaptive period (Fig. 3a). Mild alkaline hydrolysis (Kates, 1972) of PE and PG samples showed that more than $90 \%$ of the radioactivity from $\left[{ }^{14} \mathrm{C}\right]$ acetate was present in the fatty acyl chains. Therefore, in order to confirm that there was no head-group turnover either, the experiments were repeated with $\left[{ }^{32} \mathrm{P}\right]$ phosphate. As with $\left[{ }^{14} \mathrm{C}\right]$ acetate, there was no loss of ${ }^{32} \mathrm{P}$ radioactivity from phospholipids when bacteria were resuspended in $1 \mathrm{M}-\mathrm{NaCl}$ medium, but when they were shifted-up to $3 \mathrm{M}-\mathrm{NaCl}$ medium some change occurred immediately after the shift; although there was a considerable spread of points, a subsequent, small (i.e. $10 \%$ of the total ${ }^{32} \mathrm{P}$ radioactivity in $5 \mathrm{~h}$ ) but significant decrease in ${ }^{32} \mathrm{P}$ radioactivity in both $\mathrm{PE}$ and $\mathrm{PG}$ could be seen (Fig. $3 b$ ).

A reciprocal experiment to measure the biosynthesis of phospholipids during adaptation to decreased salinity in the medium (shift-down) was performed in a manner similar to that of shift-up experiments. An exponentially growing culture in medium with $3 \mathrm{M}-\mathrm{NaCl}$ was centrifuged and resuspended in medium with $1 \mathrm{M}-\mathrm{NaCl}$ (plus a control resuspended at $3 \mathrm{M}$ $\mathrm{NaCl}$ ); samples were removed at intervals after the shift for pulse-labelling with $\left[{ }^{14} \mathrm{C}\right]$ acetate as in the shift-up experiment. As in the shift-up experiments, the rates of $\left[{ }^{14} \mathrm{C}\right]$ acetate incorporation into PG and PE also showed different time-courses. The incorporation into PE rose sharply within 5 min after the shift (S1, Fig. 4), and then slowly declined (S2-S4, Fig. 4) to the final level (S4 and S5, Fig. 4) when the growth rate of the culture reached that characteristic for $1 \mathrm{M}-\mathrm{NaCl}$. On the other hand, $\left[{ }^{14} \mathrm{C}\right]$ acetate incorporation into $\mathrm{PG}$ showed no marked initial rise, but declined gradually after an initial lag of approximately $40 \mathrm{~min}$ to a final rate which was about $50 \%$ of that for PE (Fig. $4 b$ ). 

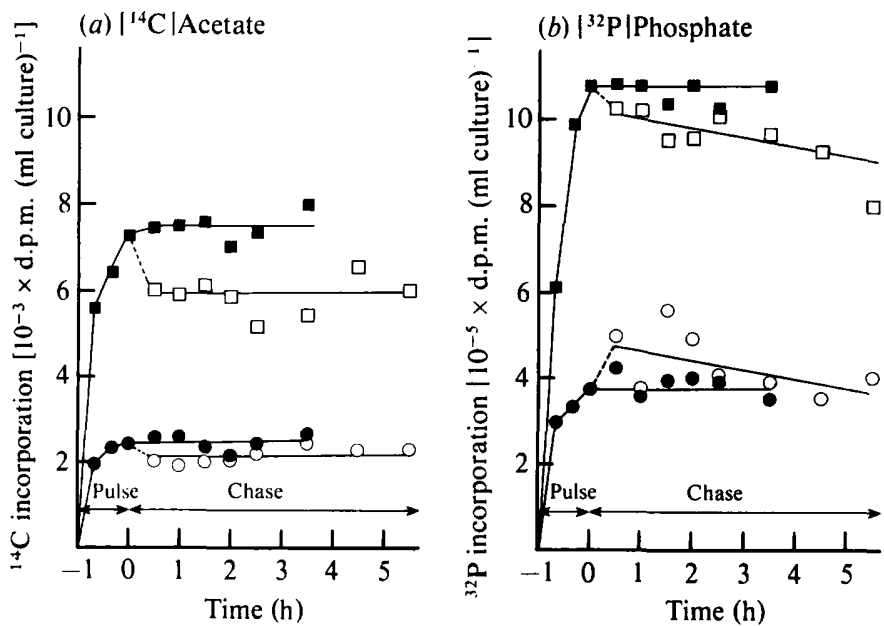

Fig. 3. Turnover of phospholipids in $V$. costicola during growth in $1 \mathrm{M}-\mathrm{NaCl}$ medium and following an increase in medium salinity. The turnover of phospholipids labelled with sodium $\left[1{ }^{14} \mathrm{C}\right] \mathrm{acetate}(a)$ or [ $\left.{ }^{32} \mathrm{P}\right]$ ]orthophosphate $(b)$ was measured by a pulse-chase method, as described in Methods. The timing of the pulse-chase is indicated on $(a)$ and $(b)$; the centrifugation and resuspension in fresh $1 \mathrm{M}$ (control) or $3 \mathrm{M}$ (shift-up) $\mathrm{NaCl}$ medium took approximately $20 \mathrm{~min}$ from the time zero shown. The radioactivity in $\mathrm{PE}$ in bacteria growing in $\mathrm{I} \mathrm{M}-\mathrm{NaCl}$ medium ( $\square$ ) and after a shift-up to $3 \mathrm{M}-\mathrm{NaCl}$ medium ( $\square$ ), and the radioactivity in $\mathrm{PG}$ in bacteria growing in $1 \mathrm{M}-\mathrm{NaCl}$ medium (O) and after a shift-up to $3 \mathrm{M}-\mathrm{NaCl}$ medium $(\mathrm{O})$ are shown.

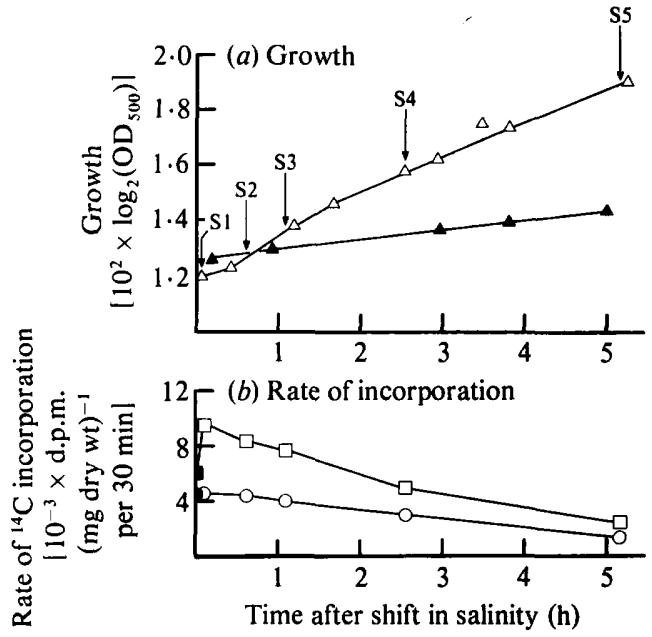

Fig. 4. Rates of incorporation of $\left[{ }^{14} \mathrm{C}\right]$ acetate into phospholipids of $V$. costicola following a decrease in medium salinity. A culture growing in medium containing $3 \mathrm{M}-\mathrm{NaCl}$ was shifted-down to $1 \mathrm{M}-\mathrm{NaCl}$, as detailed in Methods, and its growth monitored as $\operatorname{OD}_{500}(a ; \triangle)$; a control culture was centrifuged and resuspended in medium with $3 \mathrm{M}-\mathrm{NaCl}(a ; \Delta)$. At $10 \mathrm{~min}(\mathrm{~S} 1), 0.6 \mathrm{~h}(\mathrm{~S} 2), 1.1 \mathrm{~h}(\mathrm{~S} 3), 2.55 \mathrm{~h}(\mathrm{~S} 4)$ and $5.15 \mathrm{~h}$ (S5), as indicated in (a), after the shift-down the incorporation of ${ }^{14} \mathrm{C}$ radioactivity into PE ( $\square$ ) and PG $(O)$ was determined, as described in the legend to Fig. 2 and Methods. The $3 \mathrm{M}$ control culture was tested similarly at the time of the shift for its ${ }^{14} \mathrm{C}$ incorporation in PE $(\square)$ and PG (O). The rates of ${ }^{1+} \mathrm{C}$ incorporation were calculated and are summarized in $(b)$.

One of the most striking observations in both the shift-up and shift-down experiments was the immediate and opposite effect of the salt shifts on the biosynthetic rate of $\mathrm{PE}$, and to a much smaller extent on that of PG, followed by the more gradual changes in the rates of PE and PG biosynthesis during the rest of the adaptive period - when the growth rate and phospholipid composition have been shown to change (Kogut \& Russell, 1984). 


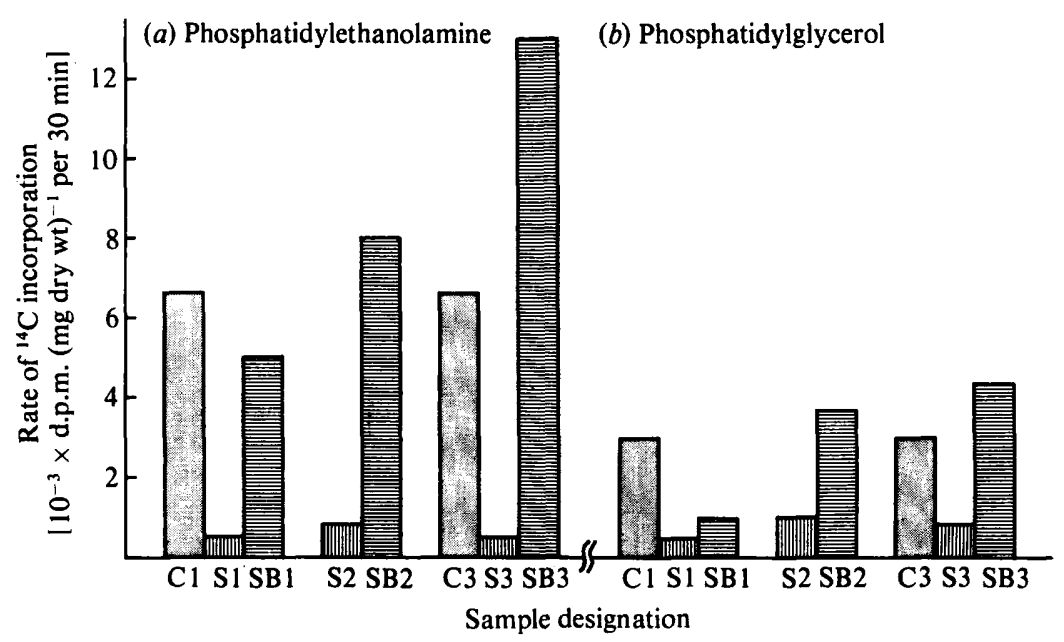

Fig. 5. The rates of incorporation of $\left[{ }^{14} \mathrm{C}\right]$ acetate into phospholipids of $V$. costicola after shifting-back to $1 \mathrm{M}-\mathrm{NaCl}$ at intervals following an increase in salt concentration from $1 \mathrm{M}$ to $3 \mathrm{M}$. The rates of incorporation of sodium $\left[1-^{-14} \mathrm{C}\right]$ acetate into PE $(a)$ and PG $(b)$ of a culture shifted-up from $1 \mathrm{M}$ - to $3 \mathrm{M}$ $\mathrm{NaCl}$ were determined at $5 \mathrm{~min}$ (S1), $3 \mathrm{~h}$ (S2) and $6 \mathrm{~h}$ (S3) after the shift-up, as in the basic shift-up experiment described in the legend to Fig. 2. All timings are taken from the time of the resuspension in $3 \mathrm{M}-\mathrm{NaCl}$ medium (i.e. initial shift-up). $1 \mathrm{M}$ control cultures ( $\mathrm{C} 1$ and $\mathrm{C} 3$ ) were tested similarly at the same time as $\mathrm{SI}$ and $\mathrm{S} 3$, respectively. In addition, portions of the shifted-up culture were shifted back to $1 \mathrm{M}-\mathrm{NaCl}$ medium (using the same protocol of centrifugation and resuspension in fresh, pre-warmed medium as in the shift-down experiments) at $2 \mathrm{~h}$ (SB1), $4 \mathrm{~h}$ (SB2) and $6 \mathrm{~h}$ (SB3) after the initial shift-up, and were tested for their ability to incorporate $\left[{ }^{14} \mathrm{C}\right]$ acetate into phospholipids as above. Although the abscissa of the figure is not a true time axis, the data for control (C), shift-up (S) and shift-back (SB) samples are placed in temporal order and in three groups which correspond to the early, middle and late stages of growth adaptation.

In order to investigate this initial effect of a salt shift in more detail, an experiment was performed in which, after an initial shift-up from $1 \mathrm{M}$ - to $3 \mathrm{M}-\mathrm{NaCl}$ medium, portions of the shifted culture were 'shifted-back' to $1 \mathrm{M}-\mathrm{NaCl}$ medium at various times, and the rates of $\left[{ }^{14} \mathrm{C}\right]$ acetate incorporation into the major phospholipids monitored as before (Fig. 5). The times for the shift-back were chosen to represent the early, middle and late stages of adaptation, monitored as in other shift experiments by following culture growth. The incorporation of acetate into PE and PG on shifting the culture from growth in $1 \mathrm{M}-\mathrm{NaCl}$ to growth in $3 \mathrm{M}-\mathrm{NaCl}$ medium followed a similar time-course as before (see Fig. 2), although the magnitude of the changes in PE and PG biosynthesis in the shifted culture were not as great as in some previous experiments. However, when portions of the culture were 'shifted back' to $1 \mathrm{M}-\mathrm{NaCl}$ after shiftup in $3 \mathrm{M}-\mathrm{NaCl}$ for $2 \mathrm{~h}, 4 \mathrm{~h}$ and $6 \mathrm{~h}$ they showed instantaneous reversal of the incorporation rate into $P E$, and to a lesser extent into PG (Fig. 5) - i.e. they returned to the relationship found in the $1 \mathrm{M}$ controls. Further incubation in $1 \mathrm{M}-\mathrm{NaCl}$ of the culture portion shifted back after $4 \mathrm{~h}$ in $3 \mathrm{M}$ $\mathrm{NaCl}$ led to a further increase of $\left[{ }^{14} \mathrm{C}\right]$ acetate incorporation rates into $\mathrm{PE}$ and $\mathrm{PG}$, the same ratio between the two rates being maintained (data not shown). Shift-back to $1 \mathrm{M}-\mathrm{NaCl}$ after $6 \mathrm{~h}$ in $3 \mathrm{M}-\mathrm{NaCl}$ (when the growth rate and phospholipid biosynthesis had fully adapted) resulted in incorporation rates into PE and PG being similar, but somewhat higher than those obtained in the shift-down experiment (Fig. 4).

\section{DISCUSSION}

The biochemical mechanisms involved in the phenotypic adaptation of moderately halophilic bacteria to growth in different salt concentrations (Kogut, 1980) have been relatively little investigated (Hipkiss et al., 1980; Bengis-Garber \& Kushner, 1982) compared with the number of studies of changes in the cellular composition (Kushner et al., 1983; Wydro et al., 1975; Ohno 
et al., 1979). Only one other group have investigated the effect of $\mathrm{NaCl}$ on phospholipid biosynthesis in halophilic bacteria. Hiramatsu et al. (1980) reported briefly that in the moderate halophile Pseudomonas halosaccharolytica relatively more $[2-14 \mathrm{C}]$ acetate was incorporated into PG than PE at higher salt concentrations. However, rates of biosynthesis were not measured and resting cell suspensions were used, so it seems doubtful that the bacteria were adapting for growth at the different salt concentrations. Our present studies show that the rates of biosynthesis of the major phospholipids alter in a complex manner following sudden changes in salinity, but are consistent with the changes in phospholipid composition during 'adaptation' to growth in different salt concentrations (Kogut \& Russell, 1984). This variation in phospholipid composition is not determined by the growth rate (Hanna et al., 1984).

There was no detectable turnover of the acyl chains or head-groups of PE and PG using $\left[{ }^{14} \mathrm{C}\right]$ acetate or $\left[{ }^{32} \mathrm{P}\right]$ phosphate, respectively, in non-shifted cultures growing in $1 \mathrm{M}-\mathrm{NaCl}$ medium (Fig. 3). The interpretation of data from cultures shifted up to $3 \mathrm{M}-\mathrm{NaCl}$ medium is more difficult, and it is not clear, for example, how the data points in Fig. 3 should be connected. There does not appear to be any turnover of ${ }^{14} \mathrm{C}$ radioactivity (Fig. $3 a$ ), but it is not obvious why there is a sudden fall in ${ }^{14} \mathrm{C}$ radioactivity immediately after the shift-up; if it were due, for example, to cell lysis and loss of recovered phospholipids, the same should have occurred when [ $\left.{ }^{32} \mathrm{P}\right]$ phosphate was used as the precursor (Fig. $3 b$ ). Instead there was a gradual $10 \%$ loss of ${ }^{32} \mathrm{P}$ radioactivity during the $5 \mathrm{~h}$ period after the shift-up (Fig. $3 \mathrm{~b}$ ). We are investigating further these differences, but in terms of the present data the incorporation rates of $\left[{ }^{14} \mathrm{C}\right]$ acetate into phospholipids in control and shifted cultures appear to represent rates of phospholipid biosynthesis, unaffected by turnover.

The time-courses of the radioactive labelling experiments reported here were matched with those carried out previously on compositional changes (Kogut \& Russell, 1984) by monitoring the growth of cultures during the adaptive period. Therefore it is possible to correlate changes in phospholipid metabolism with changes in phospholipid composition. It is clear from the data in Figs 2 and 4 that there is no strictly reciprocal relationship between the biosynthesis of negatively charged (PG) and neutral (PE) phospholipids, in response to changes in salt concentration. Furthermore, it appears that the halving of the PE/PG ratio in a shift-up experiment (Kogut \& Russell, 1984) is not brought about simply by the cessation of PE biosynthesis; although this rate falls by 30 -fold immediately after the shift, it is followed by a gradual increase in the biosynthesis of PE as the cells adapt -i.e. at a time when the PE/PG mass ratio is still dropping. Instead, this compositional change is apparently brought about mainly by the relatively smaller initial decrease (fivefold) and more rapid subsequent increase in PG biosynthesis during the early stages of adaptation to a higher salt concentration; the rate of PG biosynthesis then gradually settles to a final value, characteristic for growth in $3 \mathrm{M}-\mathrm{NaCl}$ medium.

In the reciprocal experiment, i.e. a shift-down from growth in $3 \mathrm{M}-\mathrm{NaCl}$ medium to growth in $1 \mathrm{M}-\mathrm{NaCl}$ medium, the changes in PE and PG biosynthetic rates are not the opposite of those in a shift-up experiment, although the changes in the mass ratio of PE/PG for the two types of experiment are reciprocal. After shift-down the rate of PG biosynthesis gradually declines throughout the adaptive period, whereas PE biosysnthesis rises dramatically within the first $5 \mathrm{~min}$ after the shift and then slowly settles to that characteristic for growth in $1 \mathrm{M}-\mathrm{NaCl}$, i.e. twice that of PG biosynthesis.

The shift-back experiment (i.e. reversal of the salt concentration from $3 \mathrm{M}$ to $1 \mathrm{M}$ during the shift-up adaptive period) confirms the instantaneous rise in rate of PE biosynthesis, and to a lesser extent PG biosynthesis, in response to the sudden decrease in $\mathrm{NaCl}$ concentration. This immediate effect on phospholipid biosynthesis suggests that the presence of $3 \mathrm{M}-\mathrm{NaCl}$ in the medium exerts an inhibitory action on one, or several, of the enzymes involved; moreover, the inhibition is just as instantly reversible by lowering the salt concentration.

These studies show that the response to a sudden change in salt concentration during growth of $V$. costicola, which produces gradual alteration in phospholipid composition, may involve three distinct stages and different mechanisms. (1) An immediate inhibition by high salt concentration of one or more enzymes involved in phospholipid biosynthesis, and its relief on 
lowering the salt concentration. (2) A subsequent rapid increase in the rate of PG biosynthesis at the higher salt concentration which could be due to enzyme regulation or increased enzyme production. (3) Finally, during the later stages of adaptation to growth in the new salt concentration, a more gradual adjustment in the biosynthesis of both PE and PG, more or less in parallel. This may be the result of more general regulatory processes governing phospholipid biosynthesis which will maintain its rate in line with the requirements for growth at given rates under specific conditions.

This raises the question of how these different effects of changes in external salt concentration are related. One suggestion is that the drastic alteration in PE biosynthesis which occurs immediately after the shift in salt concentration could act as a signal for the subsequent alterations in phospholipid biosynthesis, e.g. either directly by a change in the activity of a key enzyme, or by changing the lipid environment of one or more of the responsible enzymes which are membrane bound (Raetz, 1978). Hiramatsu et al. (1980) also found an inhibition of PE biosynthesis in Pseudomonas halosaccharolytica at high salt concentrations, but it is impossible to draw general conclusions about phospholipid biosynthesis during haloadaptation in bacteria, because no other species have been investigated. It may be of particular relevance in this context that the pathways of PE and PG biosynthesis in bacteria, which previously were believed to be quite separate (Raetz, 1978; Cronan, 1978), may under certain circumstances or in different species include a means of interconverting these two phospholipids (Yokota \& Kito, 1982; Card \& Finn, 1983; Fulco, 1984).

Enzyme induction could be involved (Kogut \& Russell, 1984), and the question of whether concurrent protein synthesis is mandatory for all of the effects of external salt concentration on phospholipid biosynthesis and composition is currently under investigation.

It is a pleasure to acknowledge the expert technical assistance of Mrs Paulette Fejer and Miss Indira Vishnubhatla. We should also like to thank The Wellcome Trust and The Royal Society for Travel Grants to N. J. Russell and M. Kogut, respectively, to visit the University of Ottawa where the majority of this work was performed.

\section{REFERENCES}

BLIGH, E. G. \& DYER, W. J. (1959). A rapid method of total lipid extraction and purification. Canadian Journal of Biochemistry and Physiology 37, 911-917.

Bengis-Garber, C. \& KUSHNER, D. J. (1982). Role of membrane-bound 5 -nucleotidase in nucleotide uptake by the moderate halophile Vibrio costicola. Journal of Bacteriology 149, 808-815.

CARD, G. L. \& FINN, D. J. (1983). Products of phospholipid metabolism in Bacillus stearothermophilus. Journal of Bacteriology 154, 294-303.

Cronan, J. E., JR (1978). Molecular biology of bacterial membrane lipids. Annual Review of Biochemistry 47, 163-189.

Forsyth, M. P. \& KuSHNER, D. J. (1970). Nutrition and distribution of salt response in populations of moderately halophilic bacteria. Canadian Journal of Microbiology 16, 253-261.

Fulco, A. J. (1984). Regulation and pathways of membrane lipid biosynthesis. In Biomembranes, vol. 12, pp. 303-327. Edited by M. Kates \& L. A. Manson. New York: Plenum.

Hanna, K., Bengis-Garber, C., Kushner, D. J., Kogut, M. \& Kates, M. (1984). The effect of salt concentration on the phospholipid and fatty acid composition of the moderate halophile Vibrio costicola. Canadian Journal of Microbiology 30, 669-675.

Hipkiss, A. R., Armstrong, D. W. \& Kushner, D. J. (1980). Protein turnover in a moderately halophilic bacterium. Canadian Journal of Microbiology 26, 196-203.
Hiramatsu, T., Ohno, Y., Hara, H., Yano, I. \& MASUI, M. (1980). Effects of $\mathrm{NaCl}$ concentration on the envelope components in a moderately halophilic bacterium, Pseudomonas halosaccharolytica. In $\mathrm{Sa}$ line Environments, Proceedings of the Japanese Conference on Halophilic Microbiology, pp. 189-199. Edited by $\mathrm{H}$. Morishita \& M. Masui. Kyoto, Japan: Nakanishi Printing Co.

KATES, M. (1972). Techniques of Lipidology: Isolation, Analysis and Identification of Lipids, pp. 436-477 and 559-564. Amsterdam: North-Holland Publishing Co.

Kogut, M. (1980). Strategies of microbial adaptability. Trends in Biochemical Sciences 5, 47-50.

Kogut, M. \& Russell, N. J. (1984). The growth and phospholipid composition of a moderately halophilic bacterium during adaptation to changes in salinity. Current Microbiology 10, 95-98.

Komaratat, P. \& Kates, M. (1975). The lipid composition of a halotolerant species of Staphylococcus epidermis. Biochimica et biophysica acta 398, 464 484.

KUSHNER, D. J. (1978). Life in high salt and solute concentrations: halophilic bacteria. In Microbial Life in Extreme Environments, pp. 318-368. Edited by D. J. Kushner. London: Academic Press.

Kushner, D. J., Hamaide, F. \& Macleod, R. A. (1983). Development of salt-resistant active transport in a moderately halophilic bacterium. Journal of Bacteriology 153, 1163-1171. 
Ohno, Y., Yano, I. \& Masui, M. (1979). Effect of $\mathrm{NaCl}$ concentration and temperature on the phospholipid and fatty acid composition of a moderately halophilic bacterium Pseudomonas halosaccharolytica. Journal of Biochemistry 85, 413-421.

RAETZ, C. R. H. (1978). Enzymology, genetics and regulation of membrane phospholipid synthesis in Escherichia coli. Microbiological Reviews 42, 614-659.
Wydro, R. M., Kogut, M. \& KuSHNER, D. J. (1975). Salt responses of ribosomes of a moderately halophilic bacterium. FEBS Letters 60, 210-215.

Yokota, K. \& KITo, M. (1982). Transfer of the phosphatidyl moiety of phosphatidylglycerol to phosphatidylethanolamine in Escherichia coli. Journal of Bacteriology 151, 952-961. 